\title{
Infrasound, human health, and adaptation: an integrative overview of recondite hazards in a complex environment
}

\author{
Michael A. Persinger
}

Received: 8 June 2013/Accepted: 6 August 2013/Published online: 12 September 2013

(C) The Author(s) 2013. This article is published with open access at Springerlink.com

\begin{abstract}
Infrasound displays a special capacity to affect human health and adaptation because its frequencies and amplitudes converge with those generated by the human body. Muscle sounds and whole-body vibrations are predominately within the 5- to 40-Hz range. The typical amplitudes of the oscillations are within 1-50 $\mu \mathrm{m}$, which is equivalent to the pressures of about $1 \mathrm{~Pa}$ and energies in the order of $10^{-11} \mathrm{~W} \mathrm{~m}^{-2}$. Infrasound sources from the natural environment originate from winds, microbaroms, geomagnetic activity, and microseisms and can propagate for millions of meters. Cultural sources originate from air moving through duct systems within buildings, large machinery, and more recently, wind turbines. There are also unknown sources of infrasound. It is important to differentiate the effects of infrasound from the awareness or experience of its presence. Moderate strength correlations occur between the incidences of infrasound and reports of nausea, malaise, fatigue, aversion to the area, non-specific pain, and sleep disturbances when pressure levels exceed about $50 \mathrm{db}$ for protracted periods. Experimental studies have verified these effects. Their validity is supported by convergent quantitative biophysical solutions. Because cells interact through the exchange of minute quanta of energy that corresponds with remarkably low levels of sound pressure produced by natural phenomena and wind turbines upon the body and its cavities, traditional standards for safety and quality of living might not be optimal.
\end{abstract}

Keywords Infrasound - Individual differences · Quantitative calculations · Natural sources $\cdot$ Man-made sources $\cdot$ Muscle sounds $\cdot$ Resonance interactions

\section{Introduction}

The human body is composed of several trillions of cells that exist within a threedimensional matrix that displays mechanical properties including intrinsic vibrations and

M. A. Persinger $(\square)$

Behavioural Neuroscience and Biomolecular Sciences Programs, Laurentian University, Sudbury, ON P3E 2C6, Canada

e-mail: mpersinger@laurentian.ca; drpersinger@neurocog.ca 
sound emissions (Oster and Jaffe 1980; Brozovich and Pollack 1983) in the range between 10 and $30 \mathrm{~Hz}$ (cycles per second). These cells and the tissues and organs they compose are exposed to mechanical or "sound" pressures and energies from a variety of natural and humanly constructed sources that propagate as waves through the air or through the ground. The time variations of mechanical pressures between approximately $20 \mathrm{~Hz}(20$ times per second) and $20,000 \mathrm{~Hz}(20 \mathrm{kHz})$ are experienced normally as sound when they stimulate the ear drum. As the frequency decreases below $100 \mathrm{~Hz}$, the tone is experienced with less continuity until $\sim 30 \mathrm{~Hz}$ where it is perceived with intermittence. The lowest frequency for tonal sensation is $\sim 20 \mathrm{~Hz}$ (Woodsworth and Schlosberg 1962). Traditionally, sound pressures below $20 \mathrm{~Hz}$ are defined as infrasound and those above $20 \mathrm{kHz}$ are ultrasound. From a biological perspective, the distinction is not discrete but can range across $\sim 100 \mathrm{~Hz}$. Within both natural and cultural contexts, the energies associated with sound are usually not restricted to a single sinusoidal or "pure" frequency but distributed across a wide spectrum (Alves-Pereira and Costelo Branco 2007) such that infrasound and low-frequency noise (ILFN $<500 \mathrm{~Hz}$ ) are considered a more realistic continuum for this domain.

At very low frequencies below $100 \mathrm{~Hz}$, the experiential effects from vibratory stimulation within the ears or generated within the whole body can appear to be the same. Airborne sound of sufficient intensity enters the body by direct absorption and stimulates non-auditory tissue that produces physiological effects essentially similar to whole-body vibrations (Stephens 1969). The distinction between whole-body mechanical vibration and direct absorption from sound pressures becomes less important as the frequency is reduced. According to Pachold and Mayton (2011), whole-body vibration involves the transfer of energies in the range of $0.5-80 \mathrm{~Hz}$ from environmental vibration to the human body through a broad contact area. This transition range $(20-100 \mathrm{~Hz})$ is also frequently associated with "perception" of subtle natural sources. For example, some people, during optimal weather conditions and time of day, experience a $20-40 \mathrm{~Hz}$ hum associated with the jet stream approximately $10 \mathrm{~km}$ overhead (Brown 1973).

Below $1 \mathrm{~Hz}$ fluctuations in pressure within the air or solid structures in contact with the body are described in seconds or periods, the time between two successive peak amplitudes. The equivalent frequency, the inverse of duration, is $\mathrm{milliHz}(\mathrm{mHz})$; a period of $1000 \mathrm{~s}$ (about $16.7 \mathrm{~min}$ ) is $1 \mathrm{mHz}$. Most of these periods or frequencies range between 5 and $7 \mathrm{mHz}$, which is the background free oscillation of the earth that is coupled with the lower atmosphere (Nishida et al. 2000), to about $10 \mathrm{~Hz}$. Their amplitudes overlap with the intrinsic oscillations of the human body. The natural sources of infrasound include severe weather systems (Goerke and Woodward 1966), special winds (Persinger 1980), microseisms, auroral activity (Wilson 1973), geomagnetic storms, and volcanic phenomena (Goerke et al. 1965). Constructed sources originate from air moving through long duct systems in large buildings and within moving vehicles such as automobiles or adjacency to operating aircraft (Costelo Branco and Alves-Pereira 2004). The linear distances between modern large buildings of different heights generate infrasound from rapid horizontal movement of air (wind). More recently, the proliferations of wind turbines have increased substantially the background stimuli associated with these frequencies.

One of the fundamental premises of the physical sciences is that structure dictates function. Small changes in the structure of molecules such as the substitution of a phosphate or a hydrogen ion can markedly affect the molecule's function and change the concentration required for its biochemical effectiveness. Large molecules have the capacity to be multifunctional depending upon the local chemical context. Phenomena manifested as waves, such as acoustic pressures or electromagnetic fields, also display 
potent configurations except they are expressed as temporal rather than spatial patterns. Pure sine waves or simple time-varying patterns are found less frequently in the environment than complex acoustic and electromagnetic patterns that have the potential to mediate information between the environment and cells at very low levels of intensities. Relying on only the average intensity overtime for these sources (such as infrasound) as indicators of their importance is about as useful as only measuring the loudness of a conversation to discern its syntactic content and meaningfulness.

To discern the potential impacts of these energies upon human health and adaptation, there must be a clear differentiation between the experiences or awareness associated with their presence and the effects from their presence. The latter does not require awareness or accurate attribution. To appreciate their potential influence, actual numerical values for the ranges of pressures and range of frequencies are essential. To accommodate the mechanisms by which they interact with the human body, knowledge of its intrinsic vibrations which would encourage resonance phenomena must be considered. This paper is an integrated overview of the general features of "infrasound" and their potential and measured biological and behavioral effects. It is not intended to be an exhaustive review. To provide context and meaningfulness to this complex issue, an interdisciplinary perspective is provided. The emphasis upon quantitative examples and solutions is purposeful to provide the reader with one perspective to appreciate the reasoning by which different disciplines derive conclusions about biophysical processes. By understanding the basic nature of forces, pressures, and energies through dimensional analysis, the reasoning upon which conclusions are based becomes available to all of us rather than to a technical few.

\section{Important considerations}

Although there are billions of physical events per second that move through the volume occupied by the body (Norretranders 1999), only those that produce some measureable change within the organism are classified as stimuli. All experience is generated by cellular activity within the human cerebrum; it is an approximately $1.5-\mathrm{kg}$ mass suspended in a fluid and more or less sealed within a relatively harder $\sim 7$-mm-thick boundary (the skull). The distinction between experiences from stimuli and the effects of stimuli has been known for decades. Recent developments in neuroscience indicate that stimuli can significantly affect the brain directly without the person's awareness.

For example, Berns et al. (1997) showed that small changes in the grammatical structure during reading that were not perceived by participants produced conspicuous local changes in discrete subsurface structures such as the anterior cingulate that is associated with emotional bonding and affect. Hoshiyama et al. (2003) demonstrated "subconscious" responses within the right hemisphere during the presentation of facial patterns even when the stimuli were presented for "subliminal" durations or once every $\sim 2 \mathrm{~s}(0.5 \mathrm{~Hz})$. In general, a "critical mass" and organization of neurons in the cerebral cortices is required for "awareness" (Fendrich et al. 1992). The brain affects all of the organs and tissue; cerebral changes, even without "awareness," can determine adaptation. The non-specific experiences that include "ill feeling," malaise, lethargy, low-level nausea, dizziness, mild apprehension, and diminished "concentration" are often reported in the presence of infrasound with or without the "awareness" of its presence.

Secondly, the greatest source of variance in human studies is individual differences. Different people can respond, if at all, quite differently to the "same" physical stimulus. For example, some individuals can become very ill in response to consuming a specific 
food, such as peanut butter, while most people consume the material without incidence. Some individuals develop nausea in response to interactive videogames while most people do not. The most well-documented cases of stimulus-specific anomalies have been reported for epileptic patients. Complex partial seizures, in particular, can be evoked by specific smells, musical cords, and even word sequences. The etiology for the hypersensitivity to very low levels of energy with a particular spatial or temporal pattern is related to an often subtle physical characteristic within the microstructure or chemistry of the person's brain. Appreciation for the importance of individual differences and vulnerabilities when considering the effects of infrasound cannot be overemphasized. Recognition of these differences (Tromp 1963) was instrumental for differentiating the powerful effects of changes in weather (air masses) or geophysical factors upon populations (Persinger 1987a, b).

For infrasound, individual variability is particularly important. Even during short-term exposures to very high pressure fluctuations, the sensitivity of subpopulations can be significant. During earlier experiments (Mohr et al. 1965) involving intense infrasound simulations of space flight for only $2 \mathrm{~min}$, reports included "tickle sensations" of the tympanic membrane, gagging, visual field vibration, middle ear pain, mild nausea, salivation, transient headache, and testicular aching. At very specific frequencies, such as $12 \mathrm{~Hz}$ with pressure fluctuations typical of natural infrasound, some but not all subjects within an office setting reported instantaneous and very intense ill-feelings (Bruel and Olesen 1973).

As described by the persistent and seminal research of Costelo Branco and AlvesPereira (2004) maintained, vocation-specific (aircraft technicians, ship machinists, and pilots) exposure to very high intensities of infrasound and low-frequency sound can produce vibroacoustic disease with very specific characteristics (pericardial thickening with no inflammatory process) and symptoms that can be differentiated from "general stress." These observations do not mean that all individuals will experience similar sensations near turbines, for example, or during intense natural conditions. These observations reiterate the importance of accommodating the complexity and differential sensitivity of individuals.

The third and perhaps most counterintuitive consideration is that the magnitude of a phenomenon at the casually observable level is not always the critical characteristic that is most biologically effective. Scaling that is the levels of spatial and temporal analyses, is important. For example, compared to the current density of a lightning strike, the charge movement along an axon of a neuron mediating action potentials would appear much smaller. However, the current densities for both phenomena are very similar (Persinger 2012).

What appears to be mundane and ineffective stimuli when presented in one form can be catastrophic when presented in another form. Within the domain of low-frequency magnetic fields with intensities similar to those encountered near computers or electronic systems, Murugan et al. (2013) recently demonstrated that planarian (a type of aquatic flatworm) exposed to a specific pattern of fields for a few hours per day dissolved within $2 \mathrm{~h}$ if another temporally structured field was applied on the fifth day but not after 1 day. The effectiveness of a stimulus pattern depends upon the information that is congruent with cell signaling and internal dynamics. Magnitude is less important. Stated alternatively, one can scream or whisper a sentence; the amplitude does not change the meaning within the syntax.

\section{The importance of physical units}

The demonstration that infrasonic stimuli affect the human body optimally requires the convergence of experimental data, congruent values from calculations employing physical 
properties, and likely mechanisms or processes. Of the seven basic standard international (SI) units by which we measure the physical world, mass (in kilograms), length (or distance in meters), and time (in seconds) are most applicable here. Distance divided by time $\left(\mathrm{m} \mathrm{s}^{-1}\right)$ is velocity and velocity per unit time $\left(\mathrm{m} \mathrm{s}^{-2}\right)$ is acceleration. The product of $\mathrm{kg}$ and $\mathrm{m} \mathrm{s}^{-2}$ is force measured in Newtons. When applied over distance $(\mathrm{m})$, the aggregate is energy, measured in Joules. A Joule per second $\left(\mathrm{J} \mathrm{s}^{-1}\right)$ is a Watt (power). Pressure is force applied over an area $\left(\mathrm{N} \mathrm{m}^{-2}\right)$ and is measured as Pascals $(\mathrm{Pa})$. Power (Watts) per $\mathrm{m}^{2}$ is power density. In the older scientific literature, pressure was recorded as dynes $\mathrm{cm}^{-2}$ for which one unit is $0.1 \mathrm{~Pa}$.

The relative amplitude compared to a threshold or limen is often measured in decibels (db) and is associated with "loudness" or hearing intensity level. The limen for a mechanical pressure variation in air to produce the sensation of a sound for the average human being is $\sim 2 \times 10^{-5} \mathrm{~Pa}$ or $\mathrm{kg} \mathrm{m}^{-1} \mathrm{~s}^{-2}$. Based upon the convention that decibel $(\mathrm{db})$ level is $20 \log _{10}\left(P_{\mathrm{a}} / P_{\mathrm{t}}\right.$, where $P_{\mathrm{a}}$ is the applied pressure and $P_{\mathrm{t}}$ is the threshold, the former absolute value for pressure is $0 \mathrm{db}$. The $\mathrm{db}$ value is the $\log$ (base 10) of the quotient multiplied by 20 . For a pressure of $2 \times 10^{-3} \mathrm{~Pa}$, the ratio is $10^{2}$. The $\log$ (base 10) of that is the superscript, 2, so the $\mathrm{db}$ level is $2 \times 20$ or $40 \mathrm{db}$. The latter is similar to a quiet conversation in a quiet room.

To appreciate the subjectivity of sound pressure levels, drop a $1-\mathrm{gm}\left(10^{-3} \mathrm{~kg}\right)$ candy disc (like a "breath saver") at arm's length from a distance of $0.5 \mathrm{~m}$ onto the hard top of a table. The sharp impact produces a brief perceived sound pressure level (SPL) according to a Radio Shack Sound Level meter (C-weighting) of between $\sim 60$ and $70 \mathrm{db}$ or $\sim 10^{-2} \mathrm{~Pa}$. On the other hand, the energy applied over the thin depth of the table from the force that generated the sound pressure experienced as $60 \mathrm{db}$ would be in the order of $10^{-6}$ Joules $(\mu \mathrm{J})$. Although this may appear to be a small amount of energy from a mechanical perspective if it were electromagnetic energy, in the form of photons, the influence would be very significant. The approximate energy to produce a discernible sensation of light in the dark-adapted human eye is about $10^{-17} \mathrm{~J}$ (Woodsworth and Schlosberg 1962). This means that if the energy that produced the brief discrete sound from the impact of the candy were electromagnetic within the visible wavelength, it would be sufficient to produce a light sensation for every person (assuming they were dark-adapted) on the planet.

The precision of description and the prediction of characteristics of phenomena are strongly dependent upon the instrumentation. As cogently argued by Alves-Pereira (1999) and Costelo Branco and Alves-Pereira (2004), the average db level that is displayed by most conventional instruments designed to detect sound pressure can underestimate the total potential energy. A measure that reflects frequency distribution (spectra) of the average amplitude of acoustic energy present in the environment, not just what is heard, is essential to understand the biobehavioral impact.

Conventional procedures indicated the average (hearing) acoustic pressure within a moving vehicle was measured to be $\sim 70 \mathrm{db}$ while the total acoustic pressure within the band of critical frequencies in the environment was actually $100 \mathrm{db}$. We have measured, while standing in a $25-\mathrm{m}$ hallway on the first floor that continued into the stairwell of a 7-story university building, infrasound pressure fluctuations of $70 \mathrm{db}$ (C-weighting). The traditional A-weighting recorded less than $50 \mathrm{db}$. The anomalous pressure waves originated from desynchronized exhaust units on the roof that were maintaining the "balanced pressure" for the multistory complex of fume hoods.

Appropriate instrumentation to discern the influence of infrasound is essential. Most building and industrial engineers utilize the A-weighting shapes for sound pressure meters. These correspond to the sensitivity of human hearing as reflected in the response of inner 
hair cells. Full-spectrum (unweighted) measures require the $\mathrm{C}$-weighted measurements that include the lower frequencies. Salt and Kaltenbach (2011) found that G-weighted measures include more infrasound components.

To demonstrate the remarkable underestimation of sound pressure from wind turbines from conventional measures, Salt and Kaltenbach (2011) measured no sound pressure with A-weighting at $10 \mathrm{~Hz}$ from wind turbine sounds. However, with C- and G-weighted and Van den Berg 2006-unweighted measures, the sound pressures at $10 \mathrm{~Hz}$ were around 40-60 db. The pressure from turbines within the 1-Hz range remained similar for the Cand G-weighted measures but was around $90 \mathrm{db}$ for the completely unweighted measure. These pressures and frequencies are well within the range sufficient to stimulate inner hair cells of the basilar membrane and the multitude of different cavities within the human body. These measurements indicate the sound pressures below $10 \mathrm{~Hz}$ are powerful sources of potential biological stimuli.

The limits of the measurements for a phenomenon that is an aggregate of several components often reflect the historical problems that elicited those measurements. The A-weighted scale was designed to simulate the filtering capacity of the human ear and to infer the risk of potential damage to that organ. Its disadvantage is the underrepresentation of pressures under $\sim 200 \mathrm{~Hz}$, that is, within the frequency range that comprises most of the classical band for infrasound. The $\mathrm{C}$-weighted scale was structured to be an optimal predictor of the ear's sensitivity to tones at relatively larger sound pressure levels and includes a wider and more or less equal weighting of gain from $\sim 10 \mathrm{kHz}$ to $\sim 50 \mathrm{~Hz}$. It may be less similar to the response profile for the ear but can be more reflective of effective experiences through other organ systems. The G-weighted scale may be less correlated with subjective loudness but is more representative of the pressure fluctuations that converge with the intrinsic properties of the human mass.

\section{The human body vibrates and emits sound}

As reported by Rohracher (1955), the human body displays microvibrations primarily between 6 and $12 \mathrm{~Hz}$ over its extent. The amplitudes of these microvibrations are typically between 1 and $5 \mu \mathrm{m}$, although when muscles are tensed, the peak-to-peak variation may approach $50 \mu \mathrm{m}$ without a change in frequency. For reference, the average width of a cell body, such as the neuron, is $\sim 10 \mu \mathrm{m}$. During sleep, the amplitude decreases to about half the waking value. Increased thyroid activity can be associated with slightly higher frequencies $(14 \mathrm{~Hz})$. The vibrations continue for several hours after death. In comparison, a displacement of only $0.3 \mu \mathrm{m}$ at $1 \mathrm{kHz}$ for $90 \mathrm{db}(0.63 \mathrm{~Pa})$ of sound pressure occurs in the tympanic membrane (Cheng et al. 2010).

That muscles emit sounds has been known for centuries. Oster and Jaffe (1980) demonstrated that the dominate frequency of muscle sound is between 22 and $28 \mathrm{~Hz}$ with sound pressure levels between 60 and $70 \mathrm{db}$. This magnitude is about $1 \%$ of the $\sim 90 \mathrm{db}$ required for the detection of sound at $25 \mathrm{~Hz}$. According to Bruel and Olesen (1973), the threshold is between 140 and $100 \mathrm{db}$ in the $1-20 \mathrm{~Hz}$ range. Consequently, most people would not hear their own muscle sounds unless they are amplified by contraction directly over the most sensitive organ for discerning pressure variations: the ears. To demonstrate this, raise the elbows and then place the thumbs over the ear openings. A vibrating sound $(\sim 20 \mathrm{~Hz})$ is perceived and becomes louder when the fists are tightened (muscles are tense).

This frequency band appears to be comprised of the fusion of large numbers of motor units (muscle fibers controlled by a single neuron) that have a fundamental twitch 
frequency of $7 \pm 1(6-8) \mathrm{Hz}$. Brozovich and Pollack (1983) showed that the sounds from sartorious muscles of tree frogs were emitted during shortening or lengthening. The durations of the muscles' sounds were $400 \pm 5 \mu$ s and were displayed every 20-40 ms. This $\mu$ s duration is remarkably congruent with the peak duration of the action potential as it moves along axons. A calculated estimate for the sound pressure from the peak acoustic power burst of $\sim 2 \mathrm{~mW}$ from the changes in the mass of muscle studied was about $0.2 \mathrm{~Pa}$ or just over $80 \mathrm{db}$.

Considering the powerful coupling (Whitman et al. 2013) between $\sim 7 \mathrm{~Hz}$ and $\sim 40-45 \mathrm{~Hz}$ (20-25 ms intervals) frequency bands that mediate information between the hippocampal formation deep within the temporal lobes and its representation within the cerebral cortices (Holz et al. 2010), this particular congruence of oscillations is directly relevant to subtle influences of "infrasound" upon consciousness and the "memory" of events. It may be relevant that parallel timing across levels of discourse appears to define biological systems from a physical perspective. For example, the time required to stack a nucleotide on a synthesizing DNA sequence in the nucleus of a cell is about 20 to $25 \mathrm{~ms}$ or between 40 and $45 \mathrm{~Hz}$ and involves $\sim 10^{-20} \mathrm{~J}$ of energy. Access to influencing the synthesis of the structural order of the DNA sequence has the potential to increase the probability of genetic modifications.

The fact that the human body is a physical structure that exhibits mechanical resonances as well as the emissions of electromagnetic energy from glucose metabolism during the resting state $\left(\sim 100 \mathrm{~W} \mathrm{~m}^{-2}\right)$ and photons $\left(\sim 10^{6}\right.$ photons $\left.\mathrm{m}^{-2} \mathrm{~s}^{-1}\right)$ emphasizes the importance of resonance phenomena from a plethora of external sources. When resonance is involved, the absolute magnitude of "how strong" the stimulus is less important than the frequency pattern and the narrow range of congruence for the intensity of the intrinsic and extrinsic vibrations. Resonance phenomena allow relatively weak stimuli that are temporally and spatially congruent with the system to interact with and significantly affect the stability of the system. In this instance, the fundamental unit is the cell.

Because the human body is not a simple oscillator but a complex waveform, different organs and volumes have different resonance solutions. Within a complex natural environment upon which is superimposed the source from modern civilization, an emergent field of stimuli occurs composed of beats and harmonics. A beat is a frequency emerging from the subtraction of two waveforms that is not itself generated directly. For example, the generation simultaneously of a 1,000 and $1,010 \mathrm{~Hz}$ sound wave is associated with the presence of a third "emergent" wave, $10 \mathrm{~Hz}$, which is the subtraction of the two. One method to extract the more accurate and physically relevant "vibrations" generated within the body and the external environment would be to employ spectra analyses. This powerful technique displays the relative power or pressure distributions across increments of frequencies and can reveal the recondite "critical" pattern of frequencies through which interactions can occur between the mixed energies within the sound and electromagnetic environment and the different loci within the human body. Spectra analysis options are now the routine components of most statistical packages and programs for personal computers.

\section{Sound experiences and related pressures and energies}

The velocity of sound in air at standard temperature and pressure is $\sim 344 \mathrm{~m} \mathrm{~s}$. Within water or steel, this value is $\sim 1,480$ and $\sim 5,600 \mathrm{~m} \mathrm{~s}$, respectively. The general difference in velocity of sound between seawater and distilled water is within the range of the velocity 
of an action potential along an axon. The velocity for infrasound given the same physical parameters of temperature and pressure within the air is the same as for normal sound. There are also pressure waves, for example from wind, that move at slower velocities.

For frequencies between $20 \mathrm{~Hz}$ and $2 \mathrm{kHz}$, the associated changes in pressure affect the tympanic membrane. For humans, this specialized aggregate of cells is about 0.9 by $0.8 \mathrm{~cm}$ with a thickness of $80 \mu \mathrm{m}$, resulting in a volume of $\sim 6 \times 10^{-9} \mathrm{~m}^{3}$. The propagation of the energetic changes from the vibration of this membrane to the basilar membrane within the cochlea and ultimately through a multitude of complex synaptic connections between the brain stem and the auditory cortex results in the multidimensional experiences of sound.

According to traditional interpretations, pitch is the psychological experience of the frequency of the sound pressure and reflects the location of energetic coupling along the basilar membrane. Stimulation closest to the oval window is experienced as higher pitch than stimulation of the membrane most distally. This proximity is the major reason that protracted exposure to very loud $>110 \mathrm{db}$ pressure fluctuations, which can damage the adjacent regions of the basilar membrane and can produce hearing permanent loss in the higher-frequency range. Loudness reflects the displacement from the "vertical" of the organ of Corti. They are the thread-like (cilia) actin-containing filaments that extend into the surrounding viscous fluid. At the threshold for perceiving a whisper, the displacement of air within the ear is the approximate width of a hydrogen atom. At the threshold of pain, the displacement is about the diameter of a cell (Cameron et al. 1992).

Sound experiences can occur without functional hearing. Profoundly, deaf participants exposed to very strong sound pressures reported experiences of dizziness, pain, and vibration within the range of $200 \mathrm{~Hz}$ to $1 \mathrm{kHz}$ (Ades et al. 1958). Lower-frequency $(<40 \mathrm{~Hz})$ mechanical energies have the capacity to affect the semicircular canals (primarily associated with balance), the otolith system, chest and abdominal cavities, and the whole body. The three pairs of semicircular canals and the otolith structures are most sensitive to infrasound frequencies around $7 \mathrm{~Hz}$ (Evans and Tempest 1972). These otolith and semicircular canals are particular sensitive to linear and angular acceleration of the head, respectively. Because the hair cells of the vestibular organs are most sensitive to frequencies below $\sim 30 \mathrm{~Hz}$, the experiences may not be identified as "sound" but could be articulated as non-specific whole-body "pressures," vestibular effects, "oddness," swaying (rather than spinning) or general discomfort.

That a specific region of the human brain responds to infrasound has been clearly demonstrated by Dommes et al. (2009). They exposed healthy volunteers to short bursts of infrasound and low-frequency sounds at 12, 36, 48, and $500 \mathrm{~Hz}$ delivered through the auditory canal during fMRI (functional magnetic resonance imaging) measurements. Conspicuous increases in signal intensity within the contralateral temporal cortices that included the primary and interpretational (secondary) regions from the auditory stimulation occurred above $70 \mathrm{db}$ for the $36 \mathrm{~Hz}$ and above $90 \mathrm{db}$ for $12 \mathrm{~Hz}$ stimuli.

\subsection{Critical but less-known characteristics of the "organ of hearing"}

The superlative research of Salt and Hullar (2010) highlights the importance of understanding the technical features of microanatomy of the inner ear. The cochlea is a series of fluid-filled cylindrical spaces that spiral around the auditory nerve and are sensitive to differential pressures changes. The membrane between the spaces, the organ of Corti, contains a row of inner hair cells and three rows of outer hair cells. The latter cells display stereocilia with variable lengths. Some of these cilia are embedded in the overlaying 
gelatinous membrane. At low frequencies, the inner cells respond to the velocity of the displacement of the basilar membrane while the outer cells respond to the actual displacement.

As would be expected in the classic principle of "structure dictates function," the two types of cells contact different types of afferent fibers. Approximately $95 \%$ of the fibers that transmit impulses that will be experienced as "hearing" are myelinated with one fiber contacting one inner hair cell. On the other hand, another type of nerve fiber, which is not myelinated, synapses with a number of outer hair cells. These fibers have been assumed to be unresponsive to sound. Unlike the inner hairs cells, there is also descending input from the brain. Salt and Hullar (2010) have shown that at $5 \mathrm{~Hz}$ the outer hair cells can be stimulated at sound pressures $40 \mathrm{db}$ below those that stimulate the inner hair cells associated with "conscious hearing." Stated alternatively, at $10 \mathrm{~Hz}$, the sound pressure level required to evoke responses in inner hair cells to experience "sound" is about $100 \mathrm{db}$. The outer hair cells respond around $60 \mathrm{db}$ or about the level of a conversation only the information would be "unconscious."

The arrangement is analogous to the rods and cones of the eye. These two sensors mediate information that is perceived as qualitatively different visual experiences. Multiple rods synapse with one fiber while usually only one cone is associated with one fiber. Rods are more responsive to lower frequencies of flicker stimulation than the cones. In addition, there is additional representation of visual information within regions of the cerebrum (the temporal lobe) other than the primary visual cortices. On the basis of the characteristics of the "turbine syndrome," one candidate for the "other" destination of cochlear input from the outer hair cells would be the interface between the insula and the medial surface of the transverse (Heschl's) gyrus where primary hearing is experienced but not recognized; the latter involves adjacent secondary areas. Although the insula's representations of the internal organs have been known for decades, more contemporary measurements have verified its strong contribution to consciousness experience, error detection, and the salience of a stimulus (Klein et al. 2013).

\section{Pressures and energies}

There are two perspectives for measuring the complex influences from the environment. They can be measured as pressure or energy, a duality similar to that of mass and energy. The fluctuation pressures required to induce the sensation of hearing in most people are minimum around 1-2 kHz. The reference for this value is $2 \times 10^{-5} \mathrm{~Pa}$ (Newton per meter square) or $0 \mathrm{db}$. The reference power density required at $1 \mathrm{kHz}$ for the detection of a sound is considered, by convention, to be $10^{-12} \mathrm{~W} \mathrm{~m}^{-2}$.

Sound pressure level from energy in $\mathrm{db}$ is $10 \times \log _{10}$ of the ratio of the applied "intensity" to the reference "intensity" $\left(I_{a} \times I_{r e f}^{-1}\right)$. The approximate equivalence between $\mathrm{db}$, pressure, and energy density for various phenomena are shown in Table 1. As aptly stated by Duck (2007), I(ref) $=10^{-12} \mathrm{~W} \mathrm{~m}^{-2}$ in air. A factor of 2 increase in sound intensity is equivalent to an increase in sound pressure level of $3 \mathrm{db}$ while a doubling of acoustic pressure $(\mathrm{Pa})$ increases sound pressure levels by an increment of $6 \mathrm{db}$. For comparison, the electromagnetic power density within a typical domicile (not adjacent to microwave towers) is between $10^{-6}$ and $10^{-4} \mathrm{~W} \mathrm{~m}^{-2}$. When a standard microwave ( $2.45 \mathrm{GHz}$ ) cooking unit is activated, the densities at $0.5 \mathrm{~m}$ increase to $\sim 1 \mathrm{~W} \mathrm{~m}^{-2}$. At a distance of $4 \mathrm{~m}$, the value is still twice that of background. 
Understanding the mechanisms or processes for the physical bases for the threshold of $20 \mu \mathrm{Pa}$ for hearing could be useful. The human being is a physical system (Persinger 1980) that can be defined as a volume of colloidal (aqueous) suspensions surrounded by a semipermeable boundary (the skin) and reinforced by calcium salts (bones). The thresholds for the detections of forces and energies should be determined by these constituents. Consequently, it is not surprising that the product for the density of water $\left(10^{3} \mathrm{~kg} \mathrm{~m}^{-3}\right)$ and the square of the multiplication of the average Rohracher displacement $\left(5 \times 10^{-6} \mathrm{~m}\right)$ and its intrinsic median variation $\left(10 \mathrm{~Hz}\right.$ or s$\left.^{-1}\right)$ is $\sim 2.5 \times 10^{-6} \mathrm{~Pa}$. If the pressures were greater, we could potentially begin to "hear" or at least "feel" the vibrations of our own body.

For 100 times the threshold value, or $2 \times 10^{-3} \mathrm{~Pa}, 20 \mu \mathrm{Pa}$, the decibel level is 40 . This is the level of quiet conversation. For a sound pressure of $1 \mathrm{~Pa}$, the associated value would be $100 \mathrm{db}$, which is a very loud sound approaching discomfort (Kryter 1970). For comparison, the average barometric pressure from the atmosphere is $\sim 101 \mathrm{kPa}$. This means the threshold for hearing a whisper from pressure variations within the $1-2 \mathrm{kHz}$ range is about 10 billion times less intense than the more or less steady pressure from the atmosphere. Yet, we do not "hear" the atmosphere. Hearing requires a pattern of frequencies and the presence of a body structure to transform those pressures into the energies of neurons that represent them in conscious experience.

The thresholds for "hearing" increase (more pressure is required) for frequencies below and above the 1-2 kHz range. For frequencies below $100 \mathrm{~Hz}$, pressure fluctuations increase by a factor of $10^{4}$. Hence, $80 \mathrm{db}$ may be required for the experience of sound, which is in the same range of fluctuating pressures produced by some of the frequency components of wind turbines. These pressures could affect brain activity within the temporal lobes even without awareness particularly when other ambient sound pressures are minimal. This does not indicate that frequencies less than $100 \mathrm{~Hz}$ do not affect human behavior. The effects would either not be experienced as sound or be influential without awareness.

\section{Intrinsic energy interactions}

Cell communication operates through the quanta of energies that can be mediated by molecules or intrinsic electromagnetic patterns including visible photons (Dotta et al. 2011;

Table 1 Approximate values for pressure ( $\mathrm{Pa}$, Pascals), intensity (or power density) in Watts per meter square, and the equivalent decibels $(\mathrm{db})$, based on $20 \mu \mathrm{N}$ per $\mathrm{m}^{2}$, for various experiences

\begin{tabular}{lllr}
\hline Experience & Pascals & Watts $\mathrm{m}^{-2}$ & $\mathrm{db}$ \\
\hline Hearing threshold $(1 \mathrm{kHz})$ & $10^{-5}$ & $10^{-12}$ & 0 \\
Whisper in quiet place & $10^{-4}$ & $10^{-10}$ & 20 \\
Quiet room or office & 10 & $10^{-7}$ & 50 \\
Talking & $10^{-2}$ & $10^{-6}$ & 60 \\
"Loud" group meeting & $10^{-1}$ & $10^{-4}$ & 80 \\
Subway or moving car & $10^{0}$ & $10^{-3}$ & 90 \\
Painful experience (jack hammer) & $10^{1}$ & $10^{0}$ & 120 \\
Turbojet engine & $10^{3}$ & $10^{4}$ & 160 \\
\hline
\end{tabular}

Multiplication of $\mathrm{Pa}$ by volume of the space under consideration is an estimate of energy in Joules 
Popp et al. 1988; Sun et al. 2010). There are several classic relationships between pressure and energy. The most common example is the product of pressure $\left(\mathrm{kg} \mathrm{m}^{-1} \mathrm{~s}^{-2}\right)$ and volume $\left(\mathrm{m}^{3}\right)$. At the threshold $\left(2 \times 10^{-5} \mathrm{~kg} \mathrm{~m}^{-1} \mathrm{~s}^{-2}\right)$ of auditory sensation at $1 \mathrm{kHz}$, the associated energy within the volume of the human tympanic membrane $\left(\sim 6 \times 10^{-9} \mathrm{~m}^{3}\right)$ is $\sim 10^{-13} \mathrm{~J}$.

Assuming the average cell that composes the tympanic membrane displays a diameter of $10 \mu \mathrm{m}$ and the typical density of cells in tissue, there would be about $6.5 \times 10^{6}$ cells. This would mean that the threshold for hearing the energy per cell would be about $10^{-20} \mathrm{~J}$. The implied time frame is one second. This is the specific range of energy associated with resting membrane potential of cells, the digital action potentials of neurons that are the substrate for information transfer within brain space and the quanta required for sequestering ligands to specific receptor sites (Persinger 2010). About $10^{-20} \mathrm{~J}$ is also the quantum of energy involved with the sequestering of 1 nucleotide base within $1 \mathrm{~ms}$ (the duration of an action potential) to a synthesizing RNA ribbon. The sequence of this digital system of base pairs determines the type of protein that is synthesized within the tissue and ultimately its structure and function. For this estimate, the elasticity parameters of the collagen fibers and other constituents within the membrane were not considered.

The importance of the cell plasma membrane becomes apparent when one appreciates that it constitutes only $\sim 1 \%$ of the volume of the cell and cells constitute about $50 \%$ of the total volume. Of the $\sim 10^{-13} \mathrm{~J}$ occurring within the entire tympanic membrane, only about $10^{-3}$ of it would be distributed within the plasma cell membrane. The constancy of $10^{-16} \mathrm{~J}$ per s within the minute volume of the cell membrane divided by the cross-sectional area of the tympanic membrane $\left(10^{-4} \mathrm{~m}^{2}\right)$ results in a power density in the order of $10^{-12} \mathrm{~W} \mathrm{~m}^{-2}$. This approach suggests that this threshold, calculated as well by other methods, is coupled strongly to the properties of the plasma cell membrane. These estimated values reiterate that very small pressures and their concentrations within a very small volume can be associated with energies whose magnitudes mediate the molecular activity and signaling pathways of every cell of the body (Persinger 2010).

That energy is neither created nor destroyed but instead changes form indicates the potential interaction between mechanical and electromagnetic sources. For example, the photon emissions from the side of the right hemisphere of the brain during periods of imagining of white light while sitting in complete darkness is about $10^{-11} \mathrm{~W} \mathrm{~m}^{-2}$ (Dotta et al. 2012). This is the same order of magnitude as the "ultraweak" luminescence emitted from slices of hippocampus (brain) tissue, the "gateway" to memory (Isojima et al. 1995). Assuming the cross-sectional area of the side of the human brain is about $10^{-2} \mathrm{~m}^{-2}$ this means that the energy associated with vivid imagination is about $10^{-13} \mathrm{~J}$, which is the same order of magnitude as the energy associated with the threshold for the "hearing" experience. For comparison, the typical background level of energies from extraterrestrial sources of cosmic rays (primarily protons) as well as ground radiation from natural sources is $\sim 10^{-13} \mathrm{~W} \mathrm{~m}^{-2}$ (Konig et al. 1981).

\section{Pain, discomfort, and tissue damage from infrasound}

The experience of discomfort and the pain is psychological phenomena generated within the cerebral cortices. The stimuli associated with these sensations frequently result in damage to tissue and its constituents, cells. One exception would be ionizing radiation where a fatal dosage is not always "experienced" at the time of exposure. In normal situations, such as when a person smashes his or her finger, there is no "pain" in the finger, 
although there may be tissue damage. Pain is the experience associated with specific patterns of cortical activity within the parietal lobes where inputs from the portions of external body are superimposed or within the insula where input from internal organs is represented. The insula is a major structure of the brain associated with aversive visceral learning. This type of learning often requires only one trial or association to be acquired and not forgotten. This is an important consideration for people living in the vicinity of constructed devices for which associated stimuli, such as their movement, shape, or presence, could become conditioned stimuli.

Experiences of pain are also associated with altered activity in the anterior cingulate the same region that is associated with emotional bonding, the feeling of well being, and the cerebral responses to "unconscious" changes in the environment. What determines the representations of these subtle neuronal patterns within conscious awareness are influenced by complex cerebral factors crudely designated as "personality." Cerebral organization that is most frequently affected by mild closed head injuries, previous episodes of brief hypoxia, or any condition that diminishes the function of inhibitory interneurons with the cerebral cortices can affect the sensitivity to normal sensory input. This is an important consequence because the default state of cerebral function is inhibitory as reflected by the prominent proportion of inhibition neurotransmitters. "Excitation," resulting in the display of an overt behavior, involves inhibition of this inhibition.

The source of tissue damage from very large pressure fluctuations is primarily related to the disruption of the cohesive forces between the cells that organize the tissue within an organ. According to Bershadsky et al. (2003), the typical cohesive forces between cells (such as fibroblasts, myocytes, and smooth muscle) of the body are in the order of $2-10 \times 10^{-9} \mathrm{~N}$ per $\mu \mathrm{m}^{2}$ or $\mathrm{nN} \mu \mathrm{m}^{-2}$. This is equivalent to between $10^{3}$ and $10^{4} \mathrm{~N} \mathrm{~m}^{-2}$ or $1-10 \mathrm{kPa}$ or between 180 and $200 \mathrm{db}$. Depending upon the frequency and resonance coupling, torsional forces from applied sound pressures would be sufficient to disrupt the intercellular cohesive forces between cells. Because the cohesive molecules that mediate these forces are effectively embedded within the cell membrane, it too would be disrupted. The subsequent opening of membrane channels and loss of cell membrane potential would contribute to cell death. Fragmented cells have been found in tissue of human subjects exposed to $>120 \mathrm{db}$ infrasound. Exposure of free intracellular organelles to the immune system can contribute to the development of autoimmune disorders. Fatal injuries may be inflicted in whole organisms at $200 \mathrm{db}$ (Brown 1973), which would likely reflect the shearing of the traction forces and adhesion molecules.

For reference, the pressure wave from an explosive material, such as the classic trinitrotoluene (TNT), displays a denotation velocity between $1.8 \times 10^{3}$ and $8 \times 10^{3} \mathrm{~m} \mathrm{~s}^{-1}$. With an air density of $1.3 \mathrm{~kg} \mathrm{~m}^{-3}$ and the square of the slower velocity, the pressure within the volume of a 70-kg human being would be between 10 and $100 \mathrm{MPa}$ or about 1,000 times larger than static barometric pressure. When present as a brief burst, the pressure is sufficient to exceed the intercellular cohesive forces between cells. The remaining force is translated into the rapid motion of separation.

Although extreme pressures at the surface of the cell disrupt its integrity, Ingber's (2003) idea that mechanotranduction of very small energies contributes significantly to cellular signaling is more relevant to the more frequent exposures to environmental levels of infrasound. The integrity of the tensile strength of a cell by balancing discontinuous compression forces with continuous tension indicates that local perturbations produce organized redistribution of forces throughout the entire structure of the cell. When the typical cohesive forces of $10^{-9} \mathrm{~N}$ are specifically applied over the typical width of a 
hydrogen atom, the energy approaches the range of $10^{-20} \mathrm{~J}$. This is a fundamental quantum of energy through which information is mediated through cellular pathways.

\section{Infrasound sources in the environment}

A sample of the various origins of infrasound as well as their frequency ranges and median pressures are summarized in Table 1.

\subsection{Natural origins and characteristics}

Turbulent motions in the air produce pressure fluctuations that crudely reflect the product of the density of air $(\rho)$ and the square of the velocity (Cook and Young 1962). For $10 \mathrm{~km}$ per hr $\left(2.7 \mathrm{~m} \mathrm{~s}^{-1}\right)$, the pressure is about $10 \mathrm{~Pa}$. For $40 \mathrm{~km}$ per h $\left(11.1 \mathrm{~m} \mathrm{~s}^{-1}\right)$, the "random" pressure variations would be $160 \mathrm{db}$. Wind speed is usually not constant but varies such that the random pressure fluctuations $(\Delta v)$ are more optimally described by $\rho v \Delta v$. If the wind varied irregularly between 20 and $25 \mathrm{~km}$ per h, the random fluctuations would be about $10 \mathrm{~Pa}$. During a minimal discernible "breeze," $0.5 \mathrm{~m} \mathrm{~s}^{-1}$, the pressure would be in the order of $1 \mathrm{~Pa}$. Frequent sources of infrasound pressures vary from 0.01 to $5 \mathrm{~Pa}$. Consequently, infrasound would be less masked by wind pressures on very quiet days or nights (Table 2).

Microseisms exhibit frequencies between about 0.1 and $1 \mathrm{~Hz}$ with amplitudes between 1 and $20 \mu \mathrm{m}$ along the west coast of Europe during low-pressure air masses over the adjacent ocean. The amplitude is within the range displayed by whole-body natural vibrations. The approximate equivalent pressure in air would be its density multiplied by the square of the displacement amplitude and the frequency or between $10^{-7}$ to $\sim 10^{-5} \mathrm{~Pa}$. However, in water $\left(10^{3} \mathrm{~kg} \mathrm{~m}^{-3}\right)$, the major constituent of human organisms, the latter pressure waves at $1 \mathrm{~Hz}$ would be $\sim 0.01 \mathrm{~Pa}$ or, using $20 \mu \mathrm{Pa}$ as the threshold, about $60 \mathrm{db}$. This could be physiologically effective but not experienced as sound. There are also very transient sources such as during auroral activity (Wilson 1973) and passage of meteors through the atmosphere (ReVelle 1975).

Cook and Young (1962), measuring from Washington D.C., reported robust infrasound with periods between 20 and several hundreds of seconds that arrived from the northeast to northwest depending upon the time of night. They displayed amplitudes of about $0.3 \mathrm{~Pa}$

Table 2 Origin and typical frequency range for "infrasound" sources and pressure ranges within the natural and cultural environments

\begin{tabular}{lll}
\hline Origin & Frequency range $(\mathrm{Hz})$ & Pressure range $(\mathrm{Pa})$ \\
\hline Mountain ranges & 01 to 1 & 0.05 to 0.7 \\
Incoming meteors & 0.02 to 0.3 & 0.06 to 0.8 \\
Tornados (1,000 km away) & 0.02 to .08 & 0.1 \\
Volcanic explosion (Bali) at WDC & $<1$ & 1 \\
Wind (15-25 mph) & Irregular $<1 \mathrm{~Hz}$ & 10 to 50 \\
Tube trains & 1 to 20 & 1 to 100 \\
Car moving, windows just open & 2 to 32 & 1 to 10 \\
Turbojet & 20 to $100 \mathrm{~Hz}$ & 100 \\
\hline
\end{tabular}

Sources for these values are indicated in the text 
with occasional excursions to $1 \mathrm{~Pa}$ within about 5-6 h after the rise in $K_{\mathrm{p}}$ values of 6 or higher. A $K_{\mathrm{p}}$ value is a logarithmic-like index of global geomagnetic activity. Quantitative values above 6 would be equivalent to $>67 \mathrm{nT}$ variations in the most disturbed component of the earth's magnetic field at midlatitudes and would be typical of a minor "geomagnetic storm." The mean durations of the enhanced infrasound were $6 \mathrm{~h}$ with a range between 1 and $24 \mathrm{~h}$.

Distal sources from volcanoes approximately one-half the earth's circumference in distance (Goerke et al. 1965) and severe passing weather systems (Goerke and Woodward 1966) are also powerful sources of infrasound. Depending upon local topography wind moving through a basin composed of irregular surfaces can generate substantial infrasound, which is easily measureable. For example, our RV-301 heliocorder (seismograph) whose sensor is fixed (Persinger et al. 2012) in bedrock within the basement of the Classroom Building registers irregular periodicities between 0.5 and $1 \mathrm{~Hz}$ when wind speeds exceed $\sim 25 \mathrm{~km}$ per $\mathrm{h}$. These synchronous perturbations display durations between 1.5 and $15 \mathrm{~s}$ with amplitudes of $\pm 1 \mathrm{~mm}$ compared to typical smooth line variation of $\pm 0.5 \mathrm{~mm}$ on windless days.

\subsection{Industrial and cultural sources}

As discussed by Stephens (1969), high intensity infrasound can be produced by diesel engines or conventionally designed heating and ventilating systems in modern buildings. For example, many rooms within the author's university, particularly after "retrofitting" and "renovations," produced infrasound pressure variations that exceeded $90 \mathrm{db}$ during whole-building bulk air flow. Aircraft engines are a powerful source of infrasound and low-frequency noise exceeding $120 \mathrm{db}$ across a wide spectrum (Alves-Pereira and Castello Branco 2007a, b). Large man-made objects such as ships and airplanes can behave as intrinsic oscillators of infrasound. The experiments and equipment constructed by Gavreau (1968) and his colleagues (Gavreau et al. 1966), which produced extremely powerful (kW) "pure" infrasound waves, appear to have been forgotten. Their adverse influences described as "silent killers" were discussed by Dunning (1968).

\subsection{Modern wind turbines}

Modern wind turbines, because of their size (height) and rotational velocity, have the capacity to generate significant intensities of infrasound with complex waveforms and harmonics. Assuming a rotation speed (that can change with the driving wind velocity) of 14 rotations per minute $(0.24 \mathrm{~Hz}$ multiplied three blades $=0.72 \mathrm{~Hz})$, the relative pressure level at about $100 \mathrm{~m}$ distance is about $50 \mathrm{db}$ outside a typical brick house and about $45 \mathrm{db}$ inside the dwelling. At certain frequencies, such as around 7-8 and 40-45 Hz, the magnitude of the vibration components inside and outside the house may not differ. Significant proportions of acoustic pressure are contained within the harmonic frequencies for this rotation, for example, at increments of about $1 \mathrm{~Hz}$. Some expert acoustic engineers have detected specific acoustic "fingerprints" from specific wind turbines tens of kilometers from the source. Stabilizing the structures in subsurface bedrock increases the probabilities of longer-distance transmission.

The frequency between 1 and $4 \mathrm{~Hz}$, the delta range for brain waves (electroencephalographic measures), is the one involved with slow wave (deep sleep). Disruptions in this sleep, particularly during the first approximately $5 \mathrm{~h}$ of the sleep cycle, can affect the remarkably synchronized release of hormones and proteins that facilitate tissue repair and 
normal homeostasis. The energy available from the pressure fluctuations within a human cerebral volume of $10^{-3} \mathrm{~m}^{3}$ would be equivalent to $10^{-6} \mathrm{~J}$. Assuming each neuron utilized about a $\mathrm{pJ}$ of glucose per second, the energy from the fluctuating pressure wave would be sufficient to compensate for or augment the activity of approximately a million neurons that were most active at the time. The numbers of neurons involved with the core nuclei of the brain stem controlling slow-wave sleep are within this range. Maintained, diminished brain stem concentrations of serotonin (and noradrenalin) are associated with increased incidences of depression.

A recent review by Salt and Kaltenbach (2011) described values recorded by several researchers for infrasound levels between $\sim 150$ and $750 \mathrm{~m}$ from turbines with hub heights of 62 and $36 \mathrm{~m}$ blade lengths. The sound spectrum was dominated by frequencies below $10 \mathrm{~Hz}$. Within the range of $1 \mathrm{~Hz}$, the sound pressure levels were over $90 \mathrm{db}$ when unweighted measurements were taken. These magnitudes were associated with the inaudible infrasound rather than the intermittent "swooshing" sounds that are more conspicuous. The authors emphasized the fact that people living near these turbines could be exposed $24 \mathrm{~h}$ per day for weeks that extend into years.

\subsection{Exceptional properties of infrasound}

Infrasound displays two properties that influence its biological relevance. First, its dissipation is not linear near the source. During World War I, the sound of cannon fire displayed a radius of about $100 \mathrm{~km}$ and beyond $200 \mathrm{~km}$. Between 100 and $200 \mathrm{~km}$, there was often silence. This phenomenon is due to the reflection of sound waves from heated layers of air in the upper atmosphere where the velocity is greater than sea level (Cook 1962). This distance (height) is $\sim 50 \mathrm{~km}$ where most of the strong absorption of ultraviolet energy occurs. The standing wave would be $\sim 6.6 \mathrm{mHz}$, or within the range of the free oscillations of the earth (Nishida et al. 2000).

The absorption of infrasound in air is much less for than audible sounds. Cook's (1962) calculations indicate that for a period of $10 \mathrm{~s}(0.1 \mathrm{~Hz})$, the absorption can be about $2 \times 10^{-9} \mathrm{db}$ per $\mathrm{km}$. Consequently, the loss due to absorptions within air by constraints such as viscosity and heat conduction is not significant and propagation can continue over thousands of kilometers at sea level. Effectively even when typical concentrations of water vapor are present, the energy loss is less than $1 \%$ even after propagating half-way around the earth.

\subsection{Persistent unknown sources of infrasound}

Reports of very low frequency "rumblings" and "sounds like huge machinery" apparently originating from below the observer's feet that disturb sleep and negatively affect quality of life have occurred intermittently for at least a century (Persinger and Lafreniere 1977). During the 1960s, they were attributed to Gavreau's "acoustic laser" experiments in France. Recently, the occurrence of persistent, approximately " $40 \mathrm{~Hz}$ " hums and annoying sounds apparently originating from non-specific directions or from "subterranean" locations has been reported in Taos, New Mexico; Windsor, Ontario; Calgary, Alberta; Bristol, England. Although the origins are often attributed to a local industry, the actual sources are not clear. The phenomena sometimes display diurnal variations; at other time, the amplitudes diminish or increase without the evidence of classical periodicities. There are also infrasound sources that appear to originate from local mountains (Rockaway et al. 1974). 
The unexpected origins of pervasive sources of infrasound suggest that innovation and exploration of all possibilities should at least be considered. For example, if the volume of all of the earth's oceans is assumed to be $\sim 1.3 \times 10^{18} \mathrm{~m}^{3}$, then the magnetic energy stored within them from the earth's average magnetic field intensity $\left(\sim 5 \times 10^{-5} \mathrm{~T}\right)$ would be $\sim 1.3 \times 10^{15} \mathrm{~J}$. The numbers of water molecules within this volume of water would be $\left(1.3 \times 10^{18} \mathrm{~m}^{3}\right) \cdot\left(10^{3} \mathrm{~L} \mathrm{~m}^{-3}\right) \cdot\left(5.5610^{1} \mathrm{M} \mathrm{L}^{-1}\right) \cdot\left(6.023 \times 10^{23}\right.$ molecules per M) or $\sim 4.35 \times 10^{46}$ molecules. Consequently, there would be $3 \times 10^{-32} \mathrm{~J}$ per water molecule. The temporal variation in intrinsic energy is obtained by dividing this value by Planck's constant $\left(6.626 \times 10^{-34} \mathrm{~J} \mathrm{~s}\right)$, an essential feature of quantum phenomena. The resulting frequency is $\sim 45 \mathrm{~Hz}$.

\section{Human interactions}

\subsection{Correlational studies}

That people who live in areas where there are persistent winds exhibit specific medical symptoms has been observed since the ancient Greeks. Increases in infrasound pressure during inclement weather were found to be a strong correlate of "sickness" for residents of a 16-storey hospital in Denmark when the wind was blowing (Bruel and Olesen 1973). Within large structures, such as some university buildings on the author's campus where retrofitting required large volumes of air to be displaced through long and multistory duct systems with less than optimal diameter, the infrasound affects the "attractiveness" of the room. The effect emerges after about $1 \mathrm{ks}$ of sitting and listening to lectures. One room through which vibrations were generated from unbalanced and overdesigned heating motors embedded in the floor for the hallway below was associated with unusual and frequent intraclass conflicts and emotional behaviors. When the motors were inactivated, the anomalous social behaviors ceased. Reported feelings of "uncomfortable closeness" as well as decreases in the usage time of these floors or rooms strongly suggest the aversive nature.

Green and Dunn (1968) correlated days with intense infrasound disturbances and the rates of automobile accidents and absenteeism in school children for approximately 1 month during 1967. The correlations for both associations were about $\sim 0.5$, which indicates that the two variables shared about $25 \%$ of their variance. This is a very large effect for such a "subtle" environmental stimulus. Abdominal complaints have been associated with 30-40 Hz "sounds," which were focused within the areas of about $10 \mathrm{~km}$ in diameter during periods of temperature inversions beneath the jet stream during the early morning of cool days.

The identification of vibroacoustic disease or the vibroacoustic syndrome (AlvesPereira and Castelo Branco 2007) among populations working within the aeronautical industries occurs with a specific pattern and magnitude of infrasound and low-frequency sound. The most common symptoms were sensitivity to sound, depression, irritability, preference to be socially isolated, decreased cognitive skills, sleep disruptions episodes of dizziness, and intermittent sudden tachycardia.

In my clinical experience (Persinger 1993), this collection of symptoms, including "panics," is remarkably similar to clinical patients who have been referred for neuropsychological assessment following closed head injuries (concussive effects) without formal loss of consciousness from one or more sudden impacts of mechanical forces to the body and skull from vehicular collisions or proximity to explosions (Gorham and Persinger 
2012). One of the basic premises of clinical practice in this area is that repeated "mild" concussive impacts produce adverse cumulative effects upon cognition, affect, and aging (Persinger 1995). Protracted depression for which there is no relief increases the probability of suicide.

Alves-Pereira and Castelo Branco noted a duration-dependent evolution of the reports that shifted from slight mood swings (1-4 years of exposure) to chest pain, definite mood swings, inflammation of epithelial tissue such as the skin (4-10 years) to intense muscle and joint pain, psychiatric disturbances, and persistent headaches ( $>10$ years). Within this population, there was an increase by more than a factor of 10 of late-onset epilepsies, thyroid disorders, lupus erythematous, and vitilligo. Although an epidemiological pattern of this magnitude would have received widespread attention if the stimulus was tobacco or a classic carcinogen, the significance of vibroacoustic syndromes has been largely under appreciated.

The symptoms of the vibroacoustic syndrome that differentiated it from "general stress" were the presence of low levels of blood cortisol but elevated adrenalin with the conspicuous thickening of the pericardiac muscle and no diastolic dysfunction. There is a non-specific proliferation of collagen and "elastin" in the absence of inflammatory processes. In the population of technicians they assessed, there was a marked increase of squamous cell carcinomas primarily in the upper right lobe of the lung. Electron microscopy of the microstructures within various organs such as the lung and gastrointestinal system indicated either a history of shearing or an anomalous absence of these processes. Within the cochlea, there was a fusion of cochlear cilia, a physical change the authors suggested might be a cause of the increased sensitivity to any noise reported by the patients.

\subsection{Experimental results}

Bruel and Olesen (1973) found that artificial generation of infrasound around $12 \mathrm{~Hz}$ within the $85-110 \mathrm{db}$ range elicited ill-feelings within a few seconds in several people. While infrasound pressures between 115 and $120 \mathrm{db}$ generated between 1 and $20 \mathrm{~Hz}$ did not produce visual anomalies during routine test-taking behaviors, there was a 30-40\% increase in reaction time as well as the sensation of lethargy (Evans and Tempest 1972). Application of whole-body vibrations from vertically applied sinusoidal variations displays maximum transmissibility around $5-6 \mathrm{~Hz}$ with a range between about 3 and $7 \mathrm{~Hz}$ (Stephens 1969). The frequency band with specific effects can be quite narrow. For example, sensations reported as body movements occurred in about one-third of volunteers exposed to $5-10 \mathrm{~Hz}$ vibrations, whereas visual effects were more prominent at 12,14 , and $19 \mathrm{~Hz}$. Tingling sensations were evident around $32 \mathrm{~Hz}$.

Less intense sound pressures $(80 \mathrm{db}$ ) with frequencies between 11.5 and $350 \mathrm{~Hz}$, which overlaps with infrasound, produced significant decrements in accuracy during monitoring of numbers (Beningnus et al. 1975). The presence if these sound pressures during vigilance tasks presented for $30 \mathrm{~s}$, every 3 min resulted in an approximately $60 \%$ increase in error rates. A similar observation, based upon the subjective ratings of fatigue by a large second year university class, was reported by Persinger et al. (1999). In these experiments, the large ventilation system for a classroom building was turned on or off every hour during 3 -h lectures over several weeks. Although the background pressure averaged $60 \mathrm{db}$, the peak-to-peak fluctuations varied between 1 and $5 \mathrm{db}$.

Spectral analyses indicated most of the acoustic power for the 1-5 db amplitude modulations was between 6 and $25 \mathrm{~Hz}$ (and particularly 9-20 Hz) with a mean peak 
around $13 \mathrm{~Hz}$, the primary range associated with diminished cognitive processing. About $32 \%$ of the variability in the scores (equivalent to a correlation coefficient, $r=0.57$ ) for fatigue but not for self-reported concentration could be accommodated by the conditions (fans off or on). Room temperature ranged between 21 and $24{ }^{\circ} \mathrm{C}$ while relative humidity varied between 30 and $40 \%$ each week. Measurements during lecturers in other rooms with comparable background sound pressures but without the constant amplitude variation or "limenal flutter" did not reveal the increase in subjective ratings of fatigue.

Extreme, brief periods of exposure are not always reflective of experiences associated with natural amplitudes or those produced by wind turbines. However, the symptoms may be informative. Brief ( $<120 \mathrm{~s})$ exposures to $150 \mathrm{db}$ infrasound within the $2-100 \mathrm{~Hz}$ range was investigated initially by Mohr et al. (1965) to simulate manned rocket launch conditions. Symptoms such as chest vibrations, gagging, middle ear "tickling" or pain were prominent. At $100 \mathrm{~Hz}, 153 \mathrm{db}$, symptoms included cutaneous flushing, headaches, and mild nausea. Between 63 and $70 \mathrm{~Hz}$, symptoms included choking, salivation, coughing, and pain upon swallowing.

One of the first significant animal studies by Wike et al. (1975) involved $8 \mathrm{~Hz}, 6.1 \mathrm{~mm}$ (peak to peak) whole-body vibrations. The rats quickly learned to press a bar to terminate the presentation of this stimulus, indicating its presence was aversive (negative reinforcement). The vibrated subjects pressed the lever 40-90 times per day over 30 days compared to the non-vibrated subjects' rate of $\sim 3.5$ presses per day. With an average rat weight of $\sim 0.26 \mathrm{~kg}$, the force was $\sim 10^{-1} \mathrm{~N}$. This would be equivalent to a pressure over the rat's contact area $\left(8 \times 10^{-3} \mathrm{~m}^{2}\right)$ of about $10 \mathrm{~Pa}$ or $110 \mathrm{db}$. Rats are not prone to "suggestibility" or misattribution. These results indicate that infrasound levels at amplitudes frequently found in nature or in the working spaces of large buildings with less than optimal ventilation systems or massive vibratory apparatuses on the roof can be behaviorally aversive.

The pressure fluctuations within the volume of the rat brain $\left(2.5 \times 10^{-6} \mathrm{~m}^{3}\right)$ would be energetically similar to $10^{-5} \mathrm{~J}$. With approximately $10^{9}$ equivalent cell volumes within a $2.5 \mathrm{cc}$ brain, this would mean that $\sim 10^{-14} \mathrm{~J}$ from this energy would be available per cell. This is within the range of metabolic energy associated with glucose metabolism $\left(10^{-12} \mathrm{~J} \mathrm{~s}^{-1}\right)$. The argument that the numbers of neurons that could be affected is minimal compared to the total numbers of neurons in the rat brain may not be valid in light of more recent discoveries that the experimental stimulation of only one neuron can affect behavioral responses in a detection task (Houweling and Brecht 2007) and can modify the global state of the cortical manifold (Li et al. 2009).

In order to verify the causal compared to the correlational nature of their observations for the changes in aviation technicians exposed to intense infrasound and low-frequency noise, Costelo Branco and Alves-Pereira (2004) exposed rats to continuous low-frequency noise (to simulate the conditions to which aircraft technicians were exposed) for $48 \mathrm{~h}$ followed by a week of minimal sound pressure. Microscopically conspicuous anomalies within the tracheal epithelium were apparent after the sound exposure. After approximately 2-3 days, the morphological differences were minimal in comparison with controls.

Direct measurement of the endocochlear potential by Salt et al. (2013) revealed the potential chemical mechanisms involved with infrasound effects. Knowing (1) the vestibular and tympanic scala contain fluids with typical extracellular concentrations (high in sodium) while the interfacing space (the endolymph) contains a high concentration of potassium, and (2) this differential concentration of ions, analogous to the phenomenon of the plasma membrane of a single cell, results in a potential difference of about $80 \mathrm{mV}$, they injected isotonic potassium chloride into the cochlear apex of guinea pigs. Application of 
only 5 cycles of $0.3 \mathrm{~Hz}$ but not sustained pressure to the external canal increased concentrations of potassium that were derived from pulses of endolymph driven from the sinus into the endolymphatic sac (Salt and Hullar 2010).

These are powerful experimental verifications. Viscosity ( $\mathrm{Pa} \mathrm{s}$ ) multiplied by the length of application, divided by the mass, results in a standing or "resonance" frequency. Considering the viscosity of these fluids $\left(\sim 10^{-3} \mathrm{~Pa}\right.$ s) and assuming the endolymph in the scala occupies $\sim 25 \mu \mathrm{L}$ and displays a length of $\sim 27 \mathrm{~mm}$, the standing frequency would be in the order of $0.1-0.3 \mathrm{~Hz}$. If this coincidence is meaningful, this may reflect an additional mechanism (rather than matching wavelengths) involved with the special properties of water and living aqueous systems (Del Giudice et al. 2010; Pollack 2003) by which infrasound pressures could affect this region.

Salt and Hullar (2010) showed the diminished potential difference terminated the sensor function after about $1 \mathrm{ksec}$. The change in potential difference was about $8 \mathrm{mV}$ in response to a change of pressure of $0.4 \mathrm{~Pa}$ at $5 \mathrm{~Hz}$. This is well within the magnitude of infrasound produced by many natural sources as well as wind turbines. A change of $8 \mathrm{mV}$ produces an equivalent energy on a charge $\left(1.6 \times 10^{-19} \mathrm{~A} \mathrm{~s}\right)$ of $1.3 \times 10^{-21} \mathrm{~J}$. When divided by $0.4 \mathrm{~Pa}\left(\mathrm{~kg} \mathrm{~m}^{-1} \mathrm{~s}^{-2}\right)$, this requires a volume of about $3.2 \times 10^{-21} \mathrm{~m}^{3}$ or cubic space with a width of $1.5 \times 10^{-7} \mathrm{~m}$ or $150 \mathrm{~nm}$. This is within the range of the space suggested by Salt et al. (2013) to accommodate their observations. These authors had found that responses to infrasound were discernible around only $60 \mathrm{db}$ due partially to the enhancement of differential pressure between the endolymphatic spaces relative to the perilymphatic space.

The effects of infrasound may not always be negative. There has been recent interest in employing whole-body vibration training in older people in order to increase neuromuscular adaptation and increase bone mineral density (Brooke-Wavell and Mansfield 2009). The typical frequencies involved with these studies ranged between 12 and $60 \mathrm{~Hz}$ with reported amplitudes between $55 \mu \mathrm{m}$ and $8 \mathrm{~mm}$. Exposure times range between 1 and $10 \mathrm{~min}$ while the patient stands. Assuming a mass of $70 \mathrm{~kg}$ and a displacement of $1 \mathrm{~mm}$ applied at $20 \mathrm{~Hz}$, the force would be $\sim 10^{-2} \mathrm{~N}$; the pressure through the feet $\left(\sim 10^{-3} \mathrm{~m}^{2}\right)$ would be about $10 \mathrm{~Pa}$ or the equivalent of $120 \mathrm{db}$. Alteration in muscle tonicity by classic medications such as phenobarbital $\left(50 \mathrm{mg} \mathrm{kg}^{-1}\right)$ or morphine $\left(15 \mathrm{mg} \mathrm{kg}^{-1}\right)$ alters the whole-body vibration response in dogs (Evces and McElhaney 1971).

\section{Relationships for consideration}

One of the major consequences of the shift from forces to energies during the twentieth century was the emergence of the principle that the latter was transformed rather than eliminated. When quantum considerations are incorporated (which is dependent upon frequency) and the relevance of resonance is added, the applied energies from multiple sources to a boundary condition can produce nonlinear effects within the volume. In addition to congruence or coupling of extrinsic and intrinsic frequency patterns, the additional variable is penetrability. Electromagnetic fields, particularly the magnetic field component at lower (biofrequency) ranges, and infrasound have the capacity to penetrate completely the primarily aqueous volume of the living system.

The recent shift in paradigm acknowledges the importance of minute quanta of energy, in the order of $10^{-20}$ to $10^{-19} \mathrm{~J}$ (Persinger 2010), that appears to be the fundamental bases for the resting plasma membrane potential of the average cell, the action potential of neurons, the coupling between neurotransmitters and receptors on cell membranes, and even the energy across the membrane from the effects of gravity upon the typical cell mass 
$\left(\sim 10^{-13} \mathrm{~kg}\right)$. Because a large proportion of the electromagnetic phenomena associated with this energy is within the frequency range that defines visible light and near infrared, which have been shown to participate in intercell and intracell interactions and molecular pathways (Cifra et al. 2011), physical stimuli from the environment whose magnitudes can converge with these processes have the potential to be biologically effective. The power density equivalent $\left(10^{-12} \mathrm{~W} \mathrm{~m}^{-2}\right)$ to acoustic pressure $\left(2 \times 10^{-5} \mathrm{~Pa}\right)$ for the threshold for hearing is within an order of magnitude of the energy change within the visible spectrum associated with cognitive processes (Dotta et al. 2011).

\subsection{Resonant oscillations between the solid earth and atmosphere}

The background free oscillations of the earth display amplitudes in the order of $5 \times 10^{-12} \mathrm{~m} \mathrm{~s}^{-2}$ with dominant frequencies between 3 and $5 \mathrm{mHz}$ (Nishida et al. 2000). For an average person of $70 \mathrm{~kg}$ with optimal physical coupling to these vibrations when applied over an average length of $1 \mathrm{~m}$ (for the linear width of the body), the energy would be in the order of $10^{-12} \mathrm{~W}$. If this were applied over an area of the body of between 0.1 and $1 \mathrm{~m}^{2}$, the power density would be between $10^{-12}$ and $10^{-11} \mathrm{~W} \mathrm{~m} \mathrm{~m}^{-2}$. This is within the order of magnitude associated with the energy from photons emitted from the cerebrum during cognition and within the limen for detecting $\mathrm{kHz}$ variations in mechanical pressure by the body's most sensitive transducers.

The introduction of background free oscillations to the potential effects of infrasound could be important because of the proximity of frequency range and their synergistic combinations. It may not be spurious that the standing wave between the heated levels of the upper atmosphere that is likely responsible for the unusual properties of infrasound distribution solves for this (altitude) distance. If this approach is even partially valid, then infrasound sources, particularly those from turbines or large industrial complexes, could affect sensitive populations at significant distances while intermediate areas were not or minimally affected. The influence would be diffuse as well as concentrated in areas that incidentally occupied standing nodes from this generation.

\subsection{Testing predictions from dimensional analyses for resonance}

Cameron's (1992) clever computation for the intensity of a sound wave based upon dimensional analyses, $\rho \mathrm{vA}(2 \pi \mathrm{f})^{2}$, can be applied to water, the major constituents of cells. With density or $\rho=10^{3} \mathrm{~kg} \mathrm{~m}^{-3}, v=1.48 \times 10^{3} \mathrm{~m} \mathrm{~s}^{-1}$, and $\mathrm{A}=$ area of a water molecule, radius $=0.3 \mathrm{~nm}\left(2.8 \times 10^{-19} \mathrm{~m}^{2}\right)$, and $1 \mathrm{~Hz}\left(\mathrm{~s}^{-1}\right)$ oscillation (an intermediate infrasound frequency), the "intensity" or (power density in electromagnetic equivalence) would be in the order of $10^{-12} \mathrm{~W} \mathrm{~m}^{-2}$. This power density is at the limen for discerning sound through the tympanic membrane and is within the same order of magnitude as the photon emissions from the brain during cognition.

The aggregate of units for force is $\mathrm{kg} \mathrm{m} \mathrm{s}^{-2}$. Assuming a 70-kg person displays a body vibration of $10^{-6} \mathrm{~m}(1 \mu \mathrm{m}) 10$ times per sec $\left(10^{-5} \mathrm{~m} \mathrm{~s}^{-1}\right)$, then the application of a resonant applied force within the infrasound range of $10 \mathrm{~Hz}$ would be associated with a "functional" force of $\sim 10^{-2} \mathrm{~N}$. If this were applied over a surface area, such as the human body, of $\sim 1 \mathrm{~m}^{2}$, the pressure would be in the order of $0.01 \mathrm{~Pa}$, which is equivalent to $\sim 50 \mathrm{db}$. When this same force was applied over the length of the body $(1 \mathrm{~m})$, the energy would be $\sim 10^{-2} \mathrm{~J}$. According to classical interpretations, the person would not "hear" this frequency because the threshold at this frequency is $>90 \mathrm{db}$. However, the potential to affect molecular pathways and cell function could be significant. 
Although this is four orders of magnitude less than the typical energy generated per second by the human body from the metabolism of glucose $\left(\sim 100-150 \mathrm{~J} \mathrm{~s}^{-1}\right)$, these small energies become potentially significant if they were distributed equally within the approximately 10 trillion cells (and even more bacteria) contained within the volume. Assuming the average cell width is $\sim 10 \mu \mathrm{m}$ and the approximate density of water, the mass would be $\sim 5 \times 10^{-13} \mathrm{~kg}$. Accommodating the large cavities within the body, such as the lungs and abdomen, as well as the distance between cells and the aqueous environment, the proportion of cells within the volume for a $70-\mathrm{kg}$ person would be in the order of $10 \%$ of 10 trillion cells.

Hence, the energy per cell per second would be between $\sim 10^{-16}$ and $10^{-17} \mathrm{~J}$. Assuming the average molecular reaction, such as sequestering a ligand to a receptor is about $\sim 10^{-20} \mathrm{~J}$, this would allow between $10^{3}$ and $10^{4}$ reactions to be affected. The rational basis to this approach is reflected in the boundary condition. If the applied force from resonant infrasound were at the limen of detection $\left(2 \times 10^{-5} \mathrm{~N}\right)$ and applied over the same distance the energy would be $\sim 10^{3}$ less then the above calculations and the energy per cell would be approaching $10^{-20} \mathrm{~J}$, which may be a fundamental unit for molecular interactions (Persinger 2010). These calculations suggest that a systematic approach to the effects of very weak acoustic vibrations upon molecular pathways to cells could reveal the mechanisms by which the untoward effects of infrasound might be minimized.

\subsection{Synergism between sonic (mechanical) and electromagnetic fields}

Perhaps the greatest conceptual impedances to appreciating the potential influence of infrasound is the intrinsic belief that the energies are too small to be biologically effective or that to be effective "awareness" is required. There may be a fundamental basis to the convergence between the small energies in the environment and the response windows of the body. This is very clear within the domain of the natural intensities generated by the Schumann resonance (Cherry 2002). The fundamental frequency of about 7-8 Hz and its harmonics generated between the earth and the ionosphere overlaps with the major frequency bands of the human brain. Even the temporal structure is similar (Koenig et al. 1981). In addition, the amplitudes of the magnetic (picoTesla) and electrical (mV) components of these Schumann waves are within same magnitude as the magnetic and electric components measured from the cerebral cortical manifold during different states of consciousness (Persinger and Lavalee 2012). Such convergence in form and intensity encourage resonance.

That electromagnetic energy can directly induce the experience of sound has been known since the historical experiments of Frey (1962). He investigated the perception of sounds, even by those subjects who were clinically deaf, centimeters to hundreds of meters from $\mathrm{MHz}$ and $\mathrm{GHz}$ transmitters. The radiofrequency (rf)-induced sounds were described as buzzes, clicks, "knocking," and hissing experiences depending upon the transmitter. Although the carrier frequency was between $425 \mathrm{MHz}$ and $2.9 \mathrm{GHz}$, the "sound" experiences occurred when the carriers were pulsed within the extremely low-frequency range. One effective repetition rate was 27 pulse per sec. Frey estimated on the basis of direct measurements that in very quiet conditions (around $5 \mathrm{db}$ from classical references), $\mathrm{rf}$ sounds could be induced with peak power densities of about $30 \mathrm{~mW} \mathrm{~m}^{-2}$.

The equivalences of the energies from electromagnetic and mechanical sources indicate convergence or compliment of their individual effects when they are presented simultaneously. From the perspective of parsimony, both electromagnetic and mechanical energies are the expression of the "same" entity. Their concurrence is escalating in the cultural environment. For example, sound from music presented by devices placed into the ear 
canals (as opposed to listening to music from distant speakers or instruments propagating waves through air) is also associated with a concomitant magnetic field.

The energy within a volume from a magnetic field can be estimated by $J=\left(\mathrm{B}^{2} \times(2 \times 4 \pi \mu)^{-1}\right.$ multiplied by volume, where $\mathrm{B}$ is the strength of the field and $\mu$ is permeability. Direct measurements by a power meter (AC Milligauss Meter: Model UHS2 from AlphaLab Inc) of the average magnetic field strengths from "ear buds" through which music is generated from portable devices (iPOD-touch for example) show field strengths between $10^{-7} \mathrm{~T}(1 \mathrm{mG})$ and $10^{-6} \mathrm{~T}(10 \mathrm{mG})$, depending upon the adjusted "loudness." Employing the above equation for the weakest intensity, the energy would be $4 \times 10^{-15} \mathrm{~J}$ and with a median frequency of $1 \mathrm{kHz}\left(\mathrm{s}^{-1}\right)$, the power would be $4 \times 10^{-12} \mathrm{~W}$. With an approximate area of $10^{-4} \mathrm{~m}^{2}$ for the tympanic membrane, the equivalent power density ("intensity") would be $4 \times 10^{-8} \mathrm{~W} \mathrm{~m}^{-2}$ or about $40 \mathrm{db}$. At very loud levels, the magnetic field intensity from the buds is $10^{-6} \mathrm{~T}$ so the resulting energy equivalent to acoustic pressure would be about $80 \mathrm{db}$. Phase modulation of these electromagnetic fields could facilitate the transmission of information other than that contained within the "sound patterns."

Experiments by Saroka and Persinger (2011) showed that the "conscious" choice of target words from a list of words by normal volunteers could be influenced when pronounced words were presented as only magnetic patterns in the order of $10^{-6} \mathrm{~T}(10 \mathrm{mG})$ through the temporal lobes. These intensities are similar to those experienced if the face was placed very near a computer terminal. Subsequent analyses indicated that the effect upon "choice" was mediated by the emotional dimensions (unpleasant-pleasant; passiveactive) of the words presented as electromagnetic equivalents. These quantitative solutions and experimental results indicate that energies from subtle acoustic and electromagnetic sources within the environment can affect human cognition.

\subsection{Spectra analyses of acoustic power rather than crude averages}

The maturation of a discipline of science develops from singular measures, for example intensity, to more precise measurements of the distribution of the amplitude over a temporal domain. Although average background acoustic pressures and decibel levels are excellent first-order estimates, they are similar to only employing the average microvolt fluctuations from the human brain to discern its vicissitudes. They would not be discernible. By parceling the proportions of power or energy from acoustic and mechanical sources into specific frequency units, such as the $\mu \mathrm{V}^{2} \mathrm{~Hz}^{-1}$ employed from quantitative electroencephalographic measurements, a more accurate description and specificity of symptoms and syndromes from infrasound could be accomplished.

The optimal nosology and taxonomy will no doubt be derived by thorough clinical and experimental testing. One possible classification has been suggested by Alves-Pereira and Castelo Branco (2007). Their proposed subdivision for the $0-500 \mathrm{~Hz}$ band includes partitioning of acoustic power according to $1 / 3$ octaves that would include $0-6.3,8-12.5$, 16-25, 31.5-63, 63-160, and 200-500 Hz. A more inclusive system might integrate their intervals with the peak frequencies in $\mathrm{mHz}$ (for periodicities below $1 \mathrm{~Hz}$ ) that dominate geophysical phenomena (Campbell 1967).

\section{Conclusion}

Living systems, including the human species, have evolved within a natural environment whose properties are complex but not intractable to measurement and understanding. 
Although the partitioning of the formal description of natural phenomena by different scientific disciplines may have satisfied the conditions of human cognition, the subsequent traditions may have obscured the essential relationships between human adaptation and the natural environment that is optimally discerned through true interdisciplinary approaches.

Human beings can be described as both mechanical and energetic organisms. There are multiple sources of stimuli that exhibit energetic equivalents whose values in turn converge with those essential for the function of the cell, the organ, and the organism. The frequencies that have been defined as infrasound, from natural, manufactured, and as yet unknown sources, have the capacity to resonate with the human body. This review of the scientific literature and the quantitative illustrations derived from the systematic application of known principles may facilitate the acquisition of the precision required to differentiate between natural hazards and natural benefits rather than depending primarily upon political and social agendas.

Open Access This article is distributed under the terms of the Creative Commons Attribution License which permits any use, distribution, and reproduction in any medium, provided the original author(s) and the source are credited.

\section{References}

Ades HW, Graybiel A, Morrill SN, Tolhurst GC, Nivon JL (1958) The non-auditory effects of high intensity sound stimulation on deaf human subjects. J Aviat Med 29:454-467

Alves-Pereira M (1999) Extra-aural noise-induced pathology: a review and commentary. Aviat Space Environ Med 70:A7-A21

Alves-Pereira M, Castello Branco NAA (2007a) Vibroacoustic disease: biologic effects of infrasound and low frequency noise explained by mechanotransduction cellular signaling. Prog Biophys Mol Biol 93:256-279

Alves-Pereira M, Castelo Branco NAA (2007b) Infrasound and low frequency noise dose responses: contributions. Inter-noise 2007: Istanbul Turkey: 28-31 August

Beningnus VA, Otto DA, Knelson JH (1975) Effect of low-frequency random noises on performance of a numeric monitoring task. Percept Mot Skills 40:231-239

Berns GS, Cohen JD, Mintun MA (1997) Brain regions responsiveness to novelty in the absence of awareness. Science 276:1272-1275

Bershadsky AD, Balaban NQ, Geiger B (2003) Adhesion-dependent cell mechanosensitivity. Ann Rev Cell Dev Biol 19:677-695

Brooke-Wavell K, Mansfield NJ (2009) Risks and benefits of whole body vibration training in older people. Age Aging 38:255-257

Brown R (1973) New worries about unheard sound. New Sci 60:414-416

Brozovich FV, Pollack GH (1983) Muscle contraction generates discrete sound bursts. Biophys J 41:35-40

Bruel PV, Olesen HP (1973) Infrasonic measurements. Presented Inter-noise'73 Conference: Copenhagen August 22-24, 1973

Cameron JR, Skofronick JG, Grant RM (1992) Physics of the body. Medical Physics Publishing, Madison (Wis)

Campbell WH (1967) Geomagnetic pulsations. In: Matsushita S, Campbell WH (eds) Physics of geomagnetic phenomena. Academic Press, New York, pp 821-909

Cheng JT, Aarnisalo AA, Harrington E, Hernandez-Montes E, Furlong MDS, Merchant C, Rosowski SN (2010) Motion of the surface of the human tympanic membrane measured with stroposcopic holography. Hear Res 263(1-2):66-77

Cherry N (2002) Schumann resonances: a plausible biophysical mechanism for the human health effects of solar/geomagnetic activity. Nat Hazards 26:279-331

Cifra M, Fields JT, Farhadic A (2011) Electromagnetic cellular interactions. Prog Biophys Mol Biol 105(3):223-246

Cook RK (1962) Strange sounds in the atmosphere: I. Sound 1(2):12-16

Cook RK, Young JM (1962) Strange sounds in the atmosphere: Part II. Sound 1(3):25-33

Costelo Branco NA, Alves-Pereira M (2004) Vibroacoustic disease. Noise Health 6(23):3-20 
Del Giudice E, Spinetti PR, Tedeschi A (2010) Water dynamics at the root of metamorphosis in living organisms. Water 2:566-586

Dommes E, Bauknecht HC, Scholz G, Rothemund Y, Hensel J, Klingebeil R (2009) Auditory cortex stimulation by low-frequency tones-an fMRI study. Brain Res 1304:129-137

Dotta BL, Buckner CA, Cameron D, Lafrenie RM, Persinger MA (2011) Biophoton emissions from cell cultures: biochemical evidence for the plasma membrane as the primary source. Gen Physiol Biophys 30:301-309

Dotta BL, Saroka KS, Persinger MA (2012) Increased photon emission from the head while imagining light in the dark is correlated with changes in electroencephalographic power: Support for Bokkon's biophoton hypothesis. Neurosci Lett 513:151-154

Duck FA (2007) Medical and non-medical protection standards for ultrasound and infrasound. Prog Biophys Mol Biol 93:176-191

Dunning J (1968) The silent sound that kills. Sci Mechan Jan: 31-33, 75

Evans MJ, Tempest W (1972) Some effects of infrasonic noise in transportation. J Sound Vib 22(1):19-24

Evces CR, McElhaney JH (1971) Some effects of drugs on the low frequency whole body vibration of dogs. Aerospace Med 42(4):416-428

Fendrich R, Wessinger CM, Gazzaniga MS (1992) Residual vision in a scotoma: implications for blindsight. Science 258:1489-1492

Frey AH (1962) Human auditory systems response to modulated electromagnetic energy. J Appl Physiol 17(4):689-692

Gavreau V (1968) Infrasound. Sci J 4(1):33-37

Gavreau V, Condat R, Saul H (1966) Infra-sons: generateurs, detecteurs, properietes physiques. Effets biologiques. Acustica 17(1):1-10

Goerke VH, Woodward MW (1966) Infrasonic observation of a severe weather system. Mon Weather Rev 94(6):395-398

Goerke VH, Young JM, Cook RK (1965) Infrasonic observations of the May 16, 1963, volcanic explosion on the island of Bali. J Geophys Res 70(24):6017-6022

Gorham R, Persinger MA (2012) Emergence of partial complex epilepsy-like experiences following closed head injuries: personality variables and neuropsychological profiles. Epilepsy Behav 23:152-158

Green JE, Dunn F (1968) Correlation of naturally occurring infrasonics and selected human behavior. J Acoust Soc Am 44(5):1456-1457

Holz EM, Glennon M, Prendergast K, Sauseng P (2010) Theta-gamma phase synchronization during memory matching in visual working memory. NeuroImage 52:326-335

Hoshiyama M, Kakigi R, Watanabe S, Miki K, Takeshima Y (2003) Brain responses for the subconscious recognition of faces. Neurosci Res 46:435-442

Houweling AR, Brecht M (2007) Behavioural report of a single neuron stimulation somatosensory cortex. Nature 451

Ingber DE (2003) Mechanobiology and disease of mechanotransduction. Ann Med 35:1-14

Isojima Y, Isoshima T, Nagai K, Kikuchi K, Nakagawa H (1995) Ultraweak biochemiluminesence from rat hippocampal slices. NeuroReport 6:658-660

Klein TA, Ullsperger M, Danielmeier C (2013) Error awareness and the insula: links to neurological and psychiatric disease. Front Hum Neurosci 7(14):1-14

Koenig HL, Krueger AP, Lang S, Soenning W (1981) Biological effects of environmental electromagnetism. Springer, Berlin

Kryter KD (1970) The effects of noise on man. Academic Press, New York

Li C-yT, M-m Poo, Dan Y (2009) Burst spiking of a single cortical neuron modifies global brain state. Science 324:643-645

Mohr GC, Cole JN, Guild E, von Gierke HE (1965) Effects of low frequency and infrasonic noise on man. Aerospace Med 36(9):817-824

Murugan NJ, Karbowski LM, Lafrenie RM, Persinger MA (2013) Temporally-patterned magnetic fields induce complete fragmentation in planaria. PLOSone

Nishida K, Kobayashi N, Fukao Y (2000) Resonant oscillations between the solid earth and the atmosphere. Science 287:2233-2246

Norretranders T (1999) The user illusion. Penguin, New York

Oster G, Jaffe JS (1980) Low frequency sounds form sustained muscle contraction of human skeletal muscle. Biophys J 30:119-128

Paschold HW, Mayton AG (2011) Whole-body vibration. Occupational Hazards April: 30-35

Persinger MA (1980) The weather matrix and human behavior. Praeger, New York

Persinger MA (1987a) Geopsychology and geopsychopathology: mental processes and disorders associated with geochemical and geophysical factors. Experientia 43:179-195 
Persinger MA (1987b) Human biometeorology: mental processes and disorders: a neurobehavioral perspective. Experientia 43:39-47

Persinger MA (1993) Personality changes following brain injury as a grief response to the loss of sense of self: phenomenological themes as indices of local lability and neurocognitive structuring as psychotherapy. Psychol Rep 72:1059-1068

Persinger MA (1995) Neuropsychologica principia brevita: an application to traumatic (acquired) brain injury. Psychol Rep 77:707-724

Persinger MA (2010) $10^{-20}$ Joules as neuromolecular quantum in medicinal chemistry: an alterative approach to myriad molecular pathways. Curr Med Chem 17:3094-3098

Persinger MA (2012) Brain electromagnetic activity and lightning: potentially congruent scale-invariant quantitative properties. Front Integr Neurosci 6(19):1-10

Persinger MA, Lafreniere GF (1977) Space-time transients and unusual events. Nelson-Hall, Chicago

Persinger MA, Lavalee CL (2012) The $\sum n=n$ concept and the quantitative support for the cerebralholographic and electromagnetic configurations of consciousness. J Conscious Studies 19:128-153

Persinger MA, Tiller SG, Koren SA (1999) Background sound pressure fluctuations (5 db) from overhead ventilation systems increase subjective fatigue of university students during three-hour lectures. Percept Mot Skills 88:451-456

Persinger MA, Lafreniere GF, Dotta BT (2012) Marked increases in background photon emissions in Sudbury, Ontario more than one week before the Magnitude $>8.0$ earthquakes in Japan and Chile. Int J Geosci 3:627-629

Pollack GH (2003) The role of aqueous interfaces in the cell. Adv Coll Interf Sci 103:173-196

Popp F-A, Li KH, Mei WP, Galle M, Neurohr R (1988) Physical aspects of biophotons. Experientia 44:576-585

ReVelle DO (1975) Studies of sounds from meteors. Sky and Telesc Feb: 87-90

Rockaway JW, Hower GL, Craine LB, Thomas JE (1974) Applications of ray-tracing to observations of mountain-associated infrasonic waves. Geophys J Roy Astronomical Soc 36:259-266

Rohracher H (1955) Warmehaushalt und Korpervibration. Umschau 55(22):691-692

Salt AN, Hullar TE (2010) Responses of the ear to low frequency sounds, infrasound and wind turbines. Hear Res 268:12-21

Salt AN, Kaltenbach JA (2011) Infrasound from wind turbines could affect humans. Bull Sci Technol Soc 31(4):296-302

Salt AN, Lichtenhan JT, Gill RM, Hartsock JJ (2013) Large endolymphatic potentials from low-frequency and infrasonic tones in the guinea pig. J Acoust Soc Am 133(30):1561-1571

Saroka KS, Persinger MA (2011) Detection of electromagnetic equivalents of the emotional characteristics of words: implications for the electronic-listening generation. Open Behav Sci J 5:24-27

Stephens RWB (1969) Infrasonics. Ultrasonics Jan: 30-35

Sun Y, Wang C, Dai J (2010) Biophotons as neural communication signals demonstrated by in situ biophoton autography. Photochem Photobiol Sci 9:315-322

Tromp SW (1963) Medical Biometeorology: weather, climate and the living organism. Elsevier, Amsterdam

Whitman JC, Ward LM, Woodward TS (2013) Patterns of cortical oscillations organize neural activity into whole-brain functional networks evident in MRI BOLD signal. Front Hum Neurosci 7

Wike EL, Wolfe VL, Norsworthy KA (1975) The effects of low frequency, whole body vibration on rats: prolonged training, predictability, incremental training, and taste conditioning. Bull Psychon Soc 5(4):333-335

Wilson CR (1973) Seasonal variation of auroral infrasonic wave activity. J Geophys Res 78(22):4801-4802

Woodsworth RS, Schlosberg H (1962) Experimental psychology. Rinehart and Winston, Holt 